\title{
A Test Method to Evaluate the Adhesive Property between Asphalt and Aggregate Based on Simulating Actual Working Conditions
}

\author{
Jianhua Liu ${ }^{1}$, Mutian Sun ${ }^{2, *}$, Shaoming $\mathrm{Wu}^{1}{ }^{1}$, Wenyuan Huang ${ }^{2}$, Zhenyang Fan ${ }^{1}$ and Xiaobo Du ${ }^{2}$ \\ 1 Guangzhou Airport Second Expressway Co., Ltd., Guangzhou 510470, China; 2010750@tongji.edu.cn (J.L.); \\ 1933387@tongji.edu.cn (S.W.); 2133433@tongji.edu.cn (Z.F.) \\ 2 Key Laboratory of Road and Traffic Engineering of Ministry of Education, Tongji University, Shanghai 201804, \\ China; 1931343@tongji.edu.cn (W.H.); 1710528@tongji.edu.cn (X.D.) \\ * Correspondence: 2110202@tongji.edu.cn; Tel.: +86-159-0063-3525
}

check for updates

Citation: Liu, J.; Sun, M.; Wu, S.; Huang, W.; Fan, Z.; Du, X. A Test Method to Evaluate the Adhesive Property between Asphalt and Aggregate Based on Simulating Actual Working Conditions.

Sustainability 2022, 14, 2160.

https://doi.org/10.3390/su14042160

Academic Editor: Qingli

(Barbara) Dai

Received: 29 January 2022

Accepted: 10 February 2022

Published: 14 February 2022

Publisher's Note: MDPI stays neutral with regard to jurisdictional claims in published maps and institutional affiliations.

Copyright: (c) 2022 by the authors. Licensee MDPI, Basel, Switzerland. This article is an open access article distributed under the terms and conditions of the Creative Commons Attribution (CC BY) license (https:// creativecommons.org/licenses/by/ $4.0 /)$.

\begin{abstract}
The adhesive property between asphalt and aggregate is a crucial factor that affects the resistance of asphalt pavement to moisture damage. In this study, by simulating the actual working conditions of asphalt-aggregate bonding characteristics, test equipment was developed and a method for evaluating the adhesive properties between asphalt and aggregate—the brush damage test—was proposed. A steel-wire brush as the brush type, a total of $0.5 \mathrm{~kg} / \mathrm{m}^{2}$ asphalt content, $70{ }^{\circ} \mathrm{C}$ as the maintenance temperature, and $4 \mathrm{~h}$ as the maintenance time, as well as mass loss rate (ML) of specimens before and after brushing, were used as the evaluation index. The brush damage test was conducted on five commonly used asphalt binders and two commonly used aggregates. Finally, the results of the brush damage test were analyzed in comparison with those of a binder bond strength (BBS) test. It was indicated that the evaluation results for the adhesive properties between asphalt and aggregate were not consistent under the two test methods. The pull-off tensile strength under dry conditions $\left(\mathrm{POTS}_{\mathrm{dry}}\right.$ ) and under wet conditions (POTS $\mathrm{wet}_{\text {t }}$ when ignoring the influence of the texture of aggregate did not reflect the adhesive properties. $\triangle$ POTS, representing the ability of asphalt to resist the loss of adhesion strength due to moisture damage, can be used to evaluate the adhesion properties between asphalt and aggregate. Under appropriate conditions, the brush damage test has the advantages of simple operation, high credibility, and good discrimination.
\end{abstract}

Keywords: asphalt; aggregate; moisture damage; adhesive property; brush damage test; binder bond strength test

\section{Introduction}

As a basic pavement material, the most important role of asphalt is to bond aggregates to form a solid surface for transportation. The adhesion property between asphalt and aggregate is the basic prerequisite for durability and other performance parameters of asphalt pavement [1]. Various types of road damage occur depending on time and usage, such as rutting, cracks, and moisture damage. A number of studies [2-5] have shown that such damage is closely related to the adhesion property between asphalt and aggregate.

For research on the adhesion property between asphalt and aggregate, there are many evaluation methods and indexes. At present, a unified and extensive evaluation system has not yet been formed. According to test principles, the evaluation methods include peeling evaluation, surface energy evaluation, and mechanical testing.

The peeling evaluation involves placing the asphalt-coated aggregate in water or other solvents and then evaluating, either qualitatively or quantitatively, the degree of peeling between the asphalt and the aggregate in order to determine adhesion. The boiling method and water-immersion method in the Chinese standard JTG E20-2011 [6] are intended to accelerate the peeling of asphalt from the aggregate under high-temperature 
conditions. As compared to the methods in static water immersion, the methods in dynamic water immersion simulate the scouring effect of water on the asphalt and aggregate by rotating a volumetric flask or by using ultrasonic waves to increase the severity of the test environment. These methods have been affected by subjective factors and research levels, and can be influenced by the collision between the aggregates [7-9]. Photoelectric colorimetry and the net adsorption test [10] both use spectrophotometers to measure the concentration change of the solution, which can then be used to evaluate the adhesion of asphalt and fine aggregates. However, the testing technology is difficult to use, and the applications are limited.

Surface energy evaluation is based on the change in the surface free energy of the entire system caused by the infiltration of asphalt and aggregate, and evaluates the adhesion between the asphalt and the aggregate [11,12]. According to Young's equation, the key to adopting the surface energy evaluation is to measure the surface energy parameters of asphalt, aggregate and water. The sessile drop method $[13,14]$ and Wilhelmy-plate method [15] are commonly for testing. Recently, Atomic Force Microscopy (AFM) has been used to analyze the microstructure and mechanical properties of asphalt for surface energy testing [16-18]. Testing the surface energy does not allow the direct use of aggregates with real textures for testing, as serious contact angle hysteresis will occur and influence the test results [19]. In addition, surface energy evaluation has not been widely used due to the expensive test equipment required and the complexity of test operation.

Mechanical testing mainly includes the peel test and binder bond strength (BBS) test. The peel test [20] evaluates the adhesion property by measuring the average peel force during the loading process. It is divided into $90^{\circ}$ peeling, $180^{\circ}$ peeling, rolling peeling, and T-shaped peeling [21]. However, due to the large allowable strain during the peeling process the limit of adhesion failure has yet to be determined, and the measured value is larger than the actual value [22]. The BBS test, which originally came from ASTM D4541 [23] to evaluate the bond strength in the coating industry and was later included in AASHTO TP-91 [24], has been widely as well [25-28].

Mogawer et al. [29] studied the moisture stability of a warm-mix asphalt mixture using a Hamburg wheel-track device (HWTD) and the BBS test; the results showed that there was no correlation between the HWTD test and the BBS test. However, Aguiar-Moya et al. [30] found that the BBS test had a high correlation with the HWTD test, and was not highly correlated with the surface energy test. As a result, the credibility of the BBS test has been controversial. The BBS test requires aggregates collected from the quarry as the substrates, which are first cut using diamond saw cutters to obtain a relatively flat surface and then polished to ensure consistent roughness and remove saw marks [31]. In this case, the texture and structure of the aggregate are ignored, and the asphalt film is bonded to the aggregate with a smooth surface and a uniform structure. However, in the actual adhesion behavior, aggregates often have rough surfaces and complex structures. The results of the BBS test cannot represent the adhesion property between asphalt and aggregate under actual working conditions.

In summary, the evaluation methods for the adhesion property between asphalt and aggregate have a certain degree of inaccuracy, and they are difficult to integrate with actual working conditions, where their credibility is in question. In this study, novel test equipment was independently developed, and a new evaluation method was proposed based on actual working conditions, called the "brush damage test". Taking the sample mass loss rate (ML) before and after brushing as the evaluation index, a comprehensive evaluation of the adhesion properties between five commonly used asphalts and two commonly used aggregates in pavement was conducted. In addition, a correlation analysis between the above results and the BBS test results was performed in order to clarify the effective indexes for evaluating the adhesion property between asphalt and aggregate. 


\section{Objective}

The general objective of this study was to propose an innovative testing method, the brush damage test, for evaluating the adhesion properties between asphalt and aggregate. The specific objectives were as follows:

(1) To develop the testing equipment and design the testing procedure based on testing principles appropriate to actual working conditions.

(2) To determine the experimental conditions of the brush damage test, including the brush type, the asphalt content, the maintenance temperature, and the maintenance time.

(3) To compare the results of the brush damage test with the BBS test and analyze the effective indexes to evaluate the adhesion properties between asphalt and aggregate.

\section{Materials}

Given the typical choices for adhesion research, one base asphalt binder and four modified asphalt binders were selected. The base asphalt binder was 70\#-base asphalt from Shell, which was in $70(0.1 \mathrm{~mm})$ penetration grade, referred to herein as $70 \#$. The modified asphalt binders were prepared by adding various modifiers to the base asphalt: low density polyethylene modified asphalt, Styrene-butadiene-styrene block copolymer modified asphalt, crumb rubber modified asphalt, and rubber plastic powder modified asphalt, referred to herein as LDPE, SBS, CR, and RP, respectively. The preparation process and main physical properties of these asphalt binders are summarized in Tables 1 and 2. The aggregates used in this study were $2.36-4.75 \mathrm{mmbasalt}$ and limestone, and the density test results are shown in Table 3.

Table 1. Preparation process of modified asphalt binders.

\begin{tabular}{|c|c|c|}
\hline Asphalt Binder & Modifier & Preparation \\
\hline LDPE & 6\% LDPE 868-000 & $\begin{array}{l}\text { Adding LDPE to } 70 \# \text { and stirring for } \\
75 \text { min at } 180^{\circ} \mathrm{C}\end{array}$ \\
\hline SBS & $\begin{array}{l}\text { 4\% linear SBS-791 and } 0.12 \% \\
\text { sulfur }\end{array}$ & $\begin{array}{l}\text { 1. Adding linear SBS-791 to } 70 \# \text { at } \\
180^{\circ} \mathrm{C} \text { and shearing for } 30 \mathrm{~min} \text { at } \\
3500 \mathrm{RPM} \\
\text { 2. Adding sulfur and stirring for } 2 \mathrm{~h} \\
\text { at } 180^{\circ} \mathrm{C}\end{array}$ \\
\hline $\mathrm{CR}$ & $20 \%$ crumb rubber of 30 mesh & $\begin{array}{l}\text { 1. Adding crumb rubber to } 70 \# \text { at } \\
180^{\circ} \mathrm{C} \text { and shearing for } 30 \mathrm{~min} \text { at } \\
3500 \mathrm{RPM} \\
\text { 2. Stirring for } 1 \mathrm{~h} \text { at } 180{ }^{\circ} \mathrm{C}\end{array}$ \\
\hline $\mathrm{RP}$ & $14 \%$ rubber plastic powder & $\begin{array}{l}\text { 1. Adding rubber plastic powder to } \\
\text { SBS at } 185^{\circ} \mathrm{C} \text { and shearing for } 30 \mathrm{~min} \\
\text { at } 3500 \mathrm{RPM} \\
\text { 2. Stirring for } 1.5 \mathrm{~h} \text { at } 185^{\circ} \mathrm{C}\end{array}$ \\
\hline
\end{tabular}

Table 2. Physical properties of asphalt binders.

\begin{tabular}{cccc}
\hline Asphalt Binder & $\begin{array}{c}\text { Penetration at } \mathbf{2 5}{ }^{\circ} \mathbf{C} \\
\mathbf{( 0 . 1} \mathbf{~ m m})\end{array}$ & $\begin{array}{c}\text { Softening Point } \\
\left({ }^{\circ} \mathbf{C}\right)\end{array}$ & $\begin{array}{c}\text { Ductility } \\
(\mathbf{c m})\end{array}$ \\
\hline 70\# & 62 & 46.8 & 24.3 \\
LDPE & 36 & 54.6 & 6.6 \\
SBS & 51 & 79.4 & 25.6 \\
CR & 45 & 58.4 & 7.6 \\
RP & 45 & 99.4 & 16.6
\end{tabular}

Note: The test methods of penetration, softening point, and ductility are referred to T0604-2011, T0606-2011, and T0605-2011 in Standard Test Methods of Bitumen and Bituminous Mixtures for Highway Engineering (JTG E20-2011). 
Table 3. Physical properties of aggregate.

\begin{tabular}{ccccc}
\hline Aggregate & Particle Size & $\begin{array}{c}\text { Gross Volume } \\
\text { Relative } \\
\text { Density }\end{array}$ & $\begin{array}{c}\text { Apparent } \\
\text { Relative } \\
\text { Density }\end{array}$ & $\begin{array}{c}\text { Water } \\
\text { Absorption } \\
\text { (\%) }\end{array}$ \\
\hline Basalt & $2.36-4.75 \mathrm{~mm}$ & 2.732 & 2.873 & 1.74 \\
Limestone & $2.36-4.75 \mathrm{~mm}$ & 2.692 & 2.705 & 1.82 \\
\hline
\end{tabular}

\section{Test Method}

\subsection{Test Equipment}

The test equipment used in the brush damage test was independently developed, including the loading module, the test module, and other components. The loading module was composed of a brush and a brush fixture, and the test module was composed of a test platform, a test mold, and a test-mold fixture. The main components of the equipment and the physical object are shown in Figure 1.

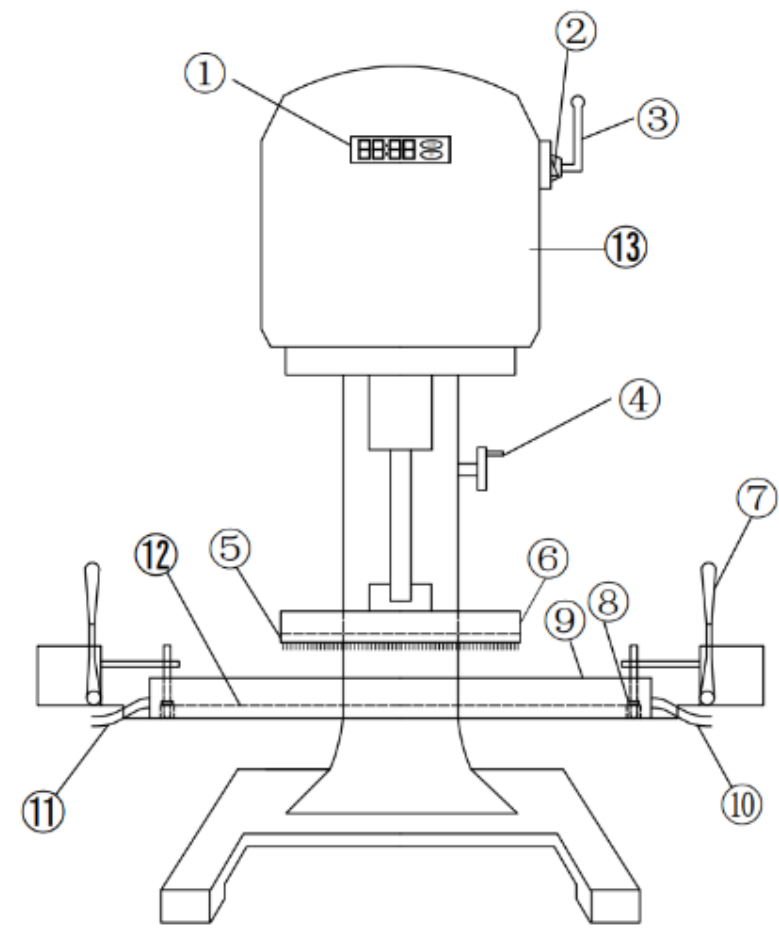

(a)

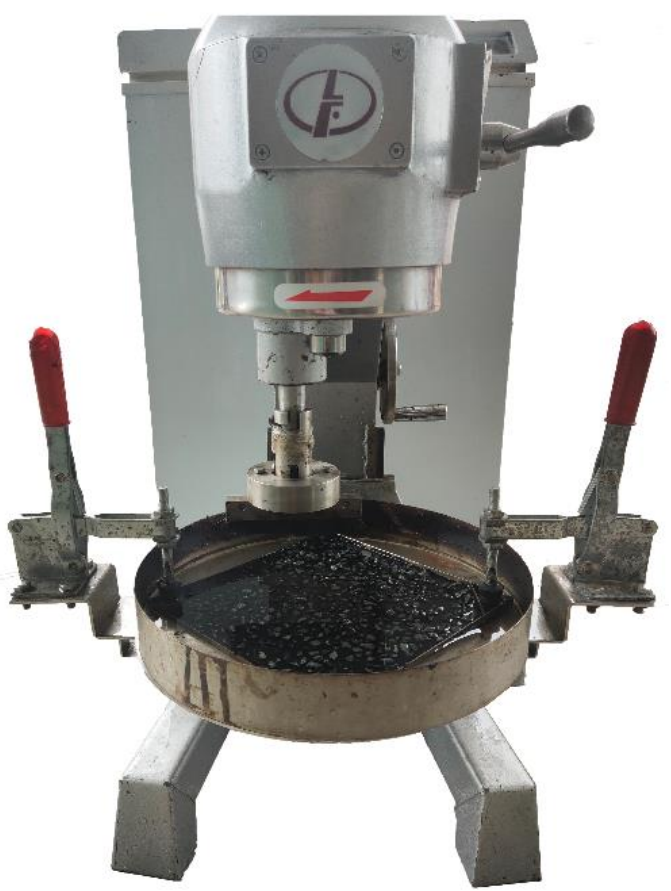

(b)

Figure 1. Test equipment: (a) main component: (1) time setting device, (2) switch, (3) gear-change lever, (4) lift lever, (5) brush, (6) brush fixture, (7) fixture wrench, (8) test-mold fixture, (9) test platform, (10) water inlet, (11) water outlet, (12) test mold, (13) equipment head; (b) physical equipment.

The specimens should be placed in the test mold and tested on the test platform. The mold was designed according to the size of the test platform, and the design drawing and physical object are shown in Figure 2. 

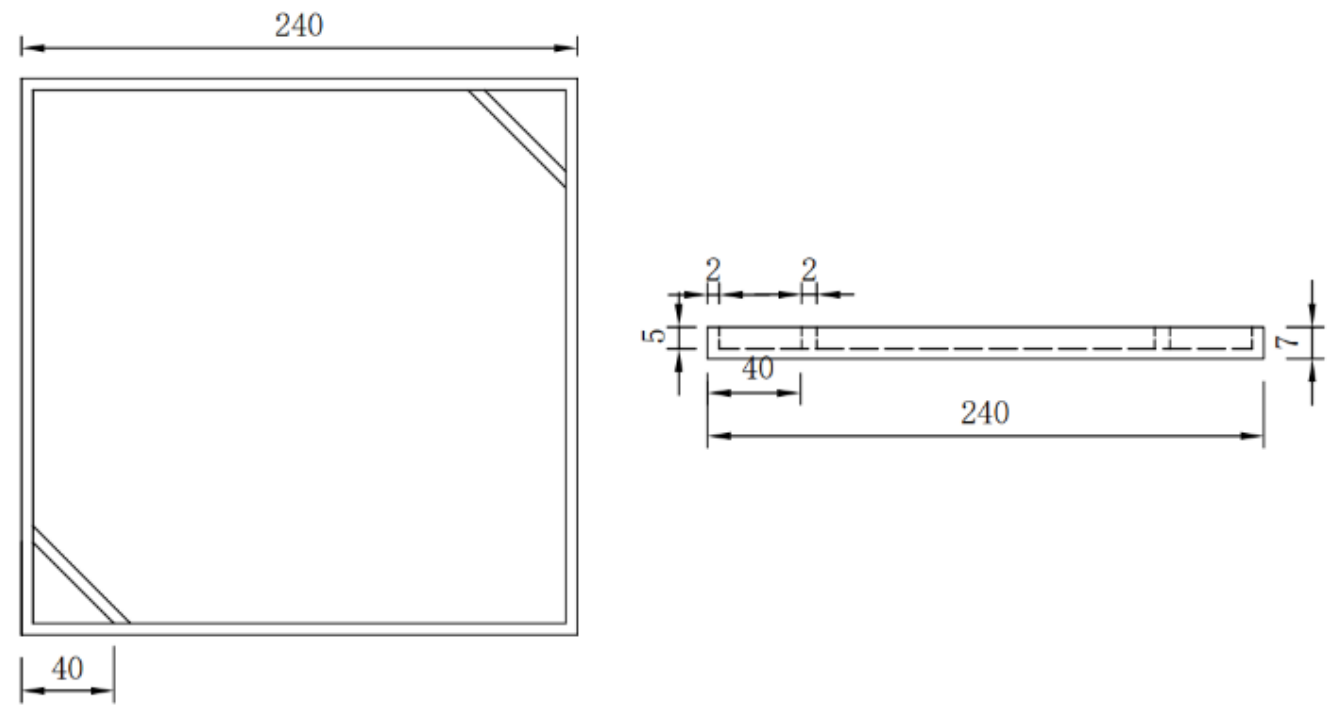

(a)

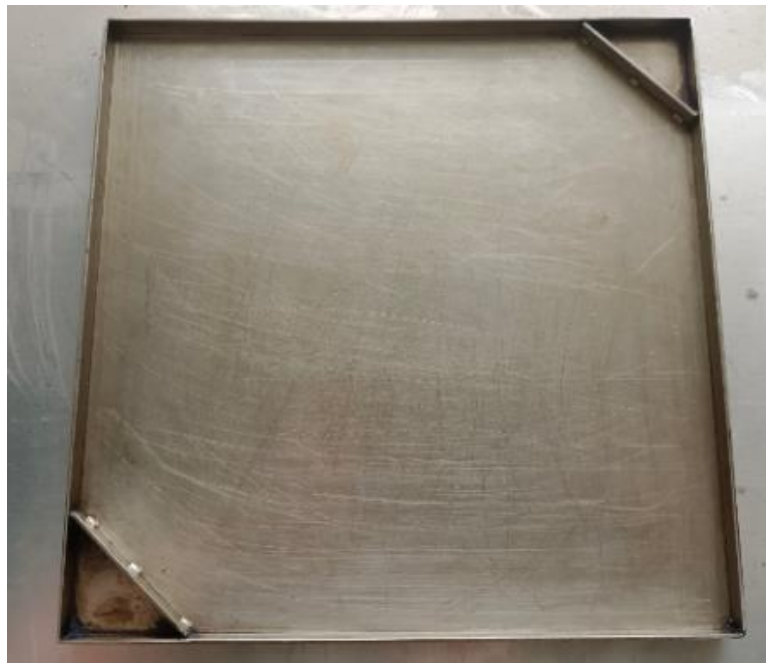

(b)

Figure 2. Test mold: (a) design (mm); (b) physical object.

\subsection{Test Procedure}

4.2.1. Preparation of Materials

(1) Aggregate

According to section T0702-2011 in Chinese standard test methods [6], the aggregates need to be dried to a constant weight at $105^{\circ} \mathrm{C}$. Equation (1) was used to determine aggregate quantity.

$$
m_{a}=\rho_{a} \times S \times \frac{2.36+4.75}{2} \times R_{f}
$$

where $m_{a}$ is aggregate quantity $(\mathrm{g}), \rho_{a}$ is apparent density of aggregate $\left(\mathrm{g} / \mathrm{cm}^{3}\right), S$ is fully paved area $\left(\mathrm{cm}^{2}\right)$, and $R_{f}$ is correction factor (\%). The method was based on the following assumptions. The shape of the aggregate is square, and the particle size is evenly distributed in an interval of $2.36-4.75 \mathrm{~mm}$. Therefore, the average height of the aggregate is taken as the average of 2.36 and 4.75 . On this basis, the mass of a single full layer of aggregate is initially obtained by multiplying the density by the volume. However, as asphalt overflow will occupy a certain position and the actual shape of the aggregate is generally not uniform, the preliminary calculation result is generally on the large side. Therefore, the correction factor needs to be considered 
in the calculation, which can be determined based on experience or pre-experiments. In this study, the correction factor of $70 \%$ was selected through pre-experiment. The aggregates need to be heated at $160^{\circ} \mathrm{C}$ for standby when using base asphalt binders, and at $180^{\circ} \mathrm{C}$ when using modified asphalt binders.

(2) Asphalt

The asphalt content has a significant impact on the test results, which should be determined according to the multi-level pre-test results by considering the expected adhesion force and particle size of the aggregate. During the preparation process, the asphalt should have acceptable fluidity. The heating temperature $\left(T_{0}\right)$ was $160{ }^{\circ} \mathrm{C}$ when using base asphalt binders, and $180^{\circ} \mathrm{C}$ when using modified asphalt binders.

\subsubsection{Preparation of Specimens}

At least three parallel specimens were prepared for each group; the specimen forming process was as follows:

(1) Weighed the mass of the test mold $\left(m_{t}\right)$ and preheated it with the asphalt in an oven set to $T_{0}$ for $1 \mathrm{~h}$.

(2) Took out the test mold and immediately poured the asphalt of target weight $\left(m_{b}\right)$ evenly.

(3) Returned the test mold to the original oven and heated for $1 \mathrm{~h}$.

(4) Placed the test mold on the heating plate set to $T_{0}$ and spread the aggregate at target weight $\left(m_{a}\right)$ evenly on the asphalt film.

(5) Used the rolling forming machine on asphalt mixture to roll the specimen for three round-trips in the same direction.

(6) Swept away all loose aggregate and cured the specimen under dry conditions at $25^{\circ} \mathrm{C}$ for $4 \mathrm{~h}$.

(7) Weighed the total mass of the test mold and specimen $\left(m_{1}\right)$.

\subsubsection{Maintenance Phase}

The specimens were divided into two test groups, and the maintenance temperature and maintenance time was determined according to their requirements. The specimens under wet conditions were first submerged in a water bath at the maintenance temperature for the maintenance time to investigate the adhesive failure and disadvantageous effects of moisture on the asphalt adhesion. Afterwards, the specimens were removed from the water, and all loose aggregate was swept away. The specimens were then kept at the maintenance temperature for $1 \mathrm{~h}$ to dry.

The specimens under dry conditions were placed in a thermostatic chamber at the maintenance temperature for a certain time. To form a contrast, the total duration of the maintenance phase of the dry group and the wet group were the same.

Finally, after sweeping away all loose aggregate, the total mass of the test mold and specimen $\left(m_{2}\right)$ were weighed.

\subsubsection{Testing Phase}

The testing phase was conducted immediately after the maintenance phase.

(1) Fixed the specimen on the test platform and raised the test platform by lift lever until the brush was in full contact with the sample.

(2) Used a speed of $100 \mathrm{r} / \mathrm{min}$ and the brushing time of $1 \mathrm{~min}$ for brush damage test. During the test, the brush rotated on the axis of the stirring shaft with its radius of rotation as the radius of the brush, and rotated with the stirring shaft with its radius of rotation of $5 \mathrm{~cm}$.

(3) Weighed the total mass of the test mold and specimen $\left(m_{3}\right)$ after sweeping away all loose aggregate. 


\subsubsection{Calculation of Results}

As there was a difference in the mass of the specimens after each molding, the mass loss rate before and after brush damage test was used for evaluation; the calculation equation was as follows:

$$
\mathrm{ML}=\frac{\left(m_{2}-m_{3}\right)}{m_{1}-m_{b}-m_{t}} \times 100 \%,
$$

where $\mathrm{ML}$ is mass loss rate (\%).

\section{Results and Discussion}

\subsection{Experimental Conditions of the Brush Damage Test}

The brush damage test analyzed four experimental conditions, specifically the type of brush, the asphalt content, the maintenance temperature, and the maintenance time.

\subsubsection{Type of Brush}

The choice of brush followed three principles:

(1) Produced substantial damage to the specimens, that is, swept away the aggregate from the specimens.

(2) The degree of damage and the test results for specimens with different properties could be differentiated.

(3) The shape of the brush was stable to ensure that no obvious deformation occurred during the test that would affect the results.

Common materials used in brush filaments include polyamide (PA), polybutylene terephthalate (PBT), polyethene (PE), polypropylene (PP), polyvinyl chloride (PVC), copper wire, steel wire, palm, and horsehair. Considering the three principles, the PP and steel wire were selected and compared, as shown in Figure 3. To reduce deformation, the brush filaments had to be densely arranged, and the length had to be reasonable for testing environment. The sizes of the two brushes are shown in Table 4.

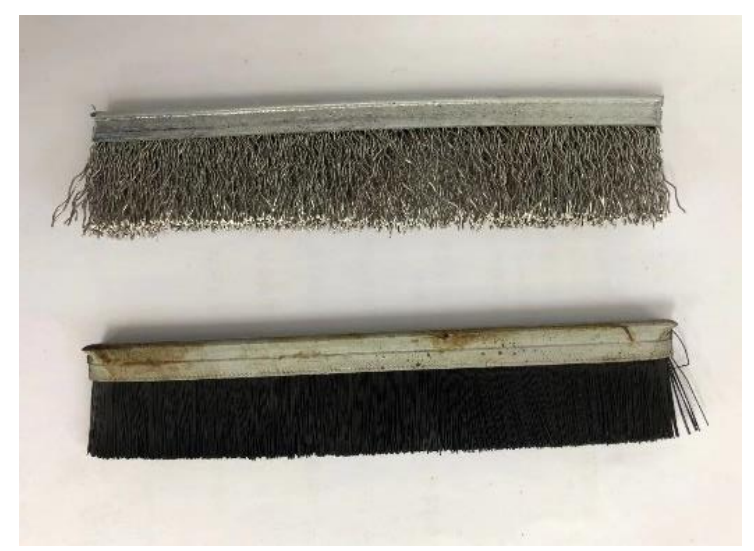

Figure 3. Two types of brushes: PP brush (bottom) and steel wire brush (top).

Table 4. Sizes of Brushes.

\begin{tabular}{cccc}
\hline Type of Brush & $\begin{array}{c}\text { Length } \times \text { Width } \times \\
\text { Height of Brush } \\
(\mathbf{m m})\end{array}$ & $\begin{array}{c}\text { Length of Brush } \\
\text { Filaments } \\
(\mathbf{m m})\end{array}$ & $\begin{array}{c}\text { Diameter of Brush } \\
\text { Filaments } \\
\mathbf{( m m})\end{array}$ \\
\hline PP Brush & $130 \times 7 \times 25$ & 17 & 0.15 \\
Steel Wire Brush & & 0.40 \\
\hline
\end{tabular}

Two sets of specimens were formed using SBS modified asphalt with $2.36-4.75 \mathrm{~mm}$ basalt aggregate. The other experimental conditions included an asphalt content of $1 \mathrm{~kg} / \mathrm{m}^{2}$, a maintenance temperature of $70{ }^{\circ} \mathrm{C}$, and a maintenance time under wet conditions of $4 \mathrm{~h}$. 
The brush damage test results using the PP brush and the steel-wire brush are shown in Figure 4.

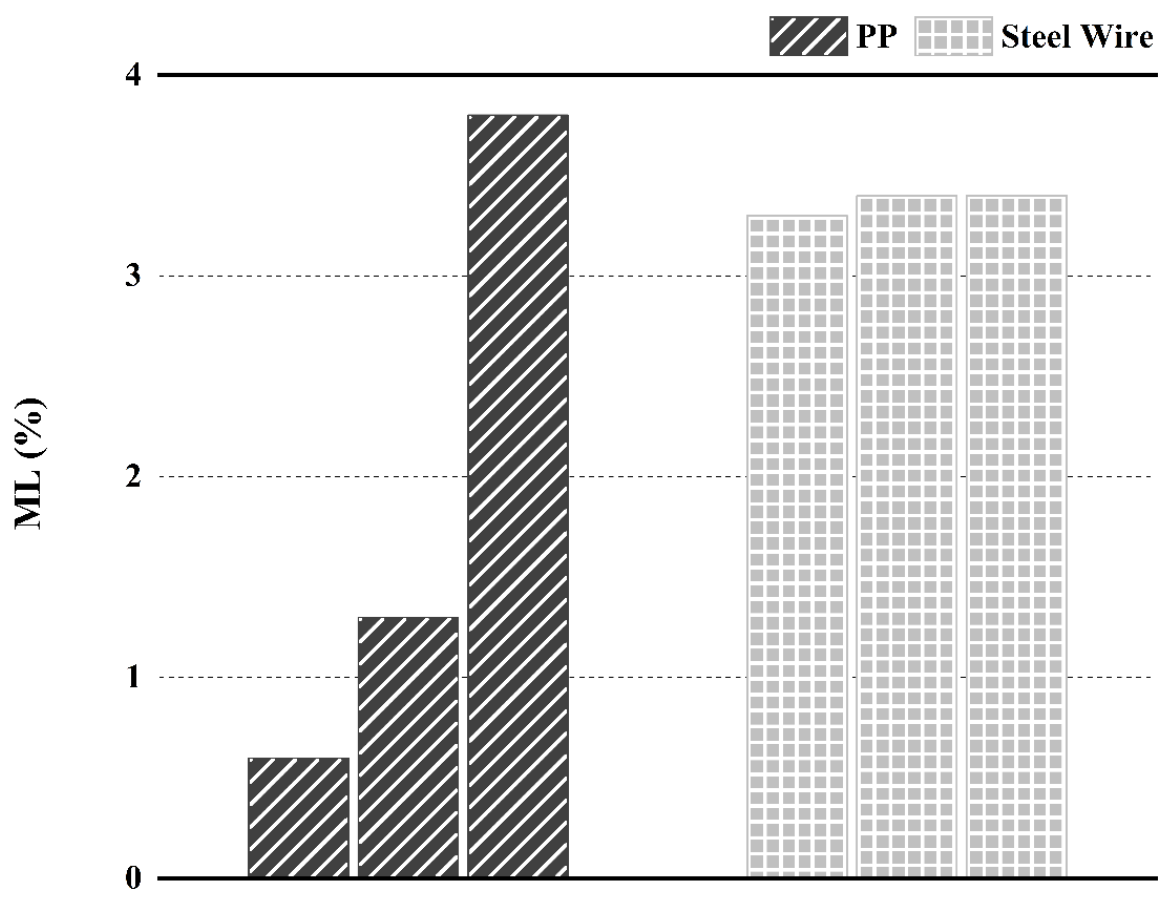

Type of Brush

Figure 4. Brush damage test results under different types of brushes.

As shown in Figure 4, as compared to the steel-wire brush, the test results of using the PP brush were more discrete. Through observation, because the temperature of the specimens was relatively high, the asphalt was easy to stick to the PP brush during the test. Due to the softness, the PP filaments bonded with the asphalt, losing their uniform distribution, and could not be restored to their original state. This phenomenon occurred randomly and then changed the contact mode of the brush and the specimens, leading to greater variability in the test results. As a comparison, the steel-wire brush had the ability to maintain a stable shape during the brushing process due to its high hardness. Hence, the steel-wire brush was chosen for the brush damage test.

\subsubsection{Asphalt Content}

Three sets of specimens were formed using SBS and RP with $2.36-4.75 \mathrm{~mm}$ basalt aggregate, and the asphalt content was $0.5 \mathrm{~kg} / \mathrm{m}^{2}, 1 \mathrm{~kg} / \mathrm{m}^{2}$ and $1.5 \mathrm{~kg} / \mathrm{m}^{2}$ respectively. The other experimental conditions included a steel-wire brush, a maintenance temperature of $70{ }^{\circ} \mathrm{C}$, and a maintenance time under wet conditions of $4 \mathrm{~h}$. The brush damage test results under different asphalt content are shown in Figure 5.

As shown in Figure 5, when the asphalt content was $0.5 \mathrm{~kg} / \mathrm{m}^{2}$ and $1.0 \mathrm{~kg} / \mathrm{m}^{2}$, the ML values of the specimens using SBS were greater than those using RP. When the asphalt content was $1.5 \mathrm{~kg} / \mathrm{m}^{2}$, the result was the opposite.

When the asphalt content was $1.5 \mathrm{~kg} / \mathrm{m}^{2}$, the thickness of the asphalt film was approximately $1.3 \mathrm{~mm}$. Due to the squeezing effect of aggregate paving, the thickness of the asphalt film was greater, causing a considerable part of the uneven and irregular flat aggregate to be mostly or completely trapped in the asphalt. Therefore, the brush could only act on the asphalt, not on the aggregate wrapped in asphalt. In addition, the viscosity of SBS is lower than that of RP at $70^{\circ} \mathrm{C}$. Through observation, part of the asphalt was picked up by the brush during the test and adhered to the surrounding aggregate, making the aggregate more difficult to brush off (as shown in Figure 6) while the asphalt was coated 
on the surface of the active area. Hence, when the asphalt content was $1.5 \mathrm{~kg} / \mathrm{m}^{2}$, the test results did not represent the actual damage.

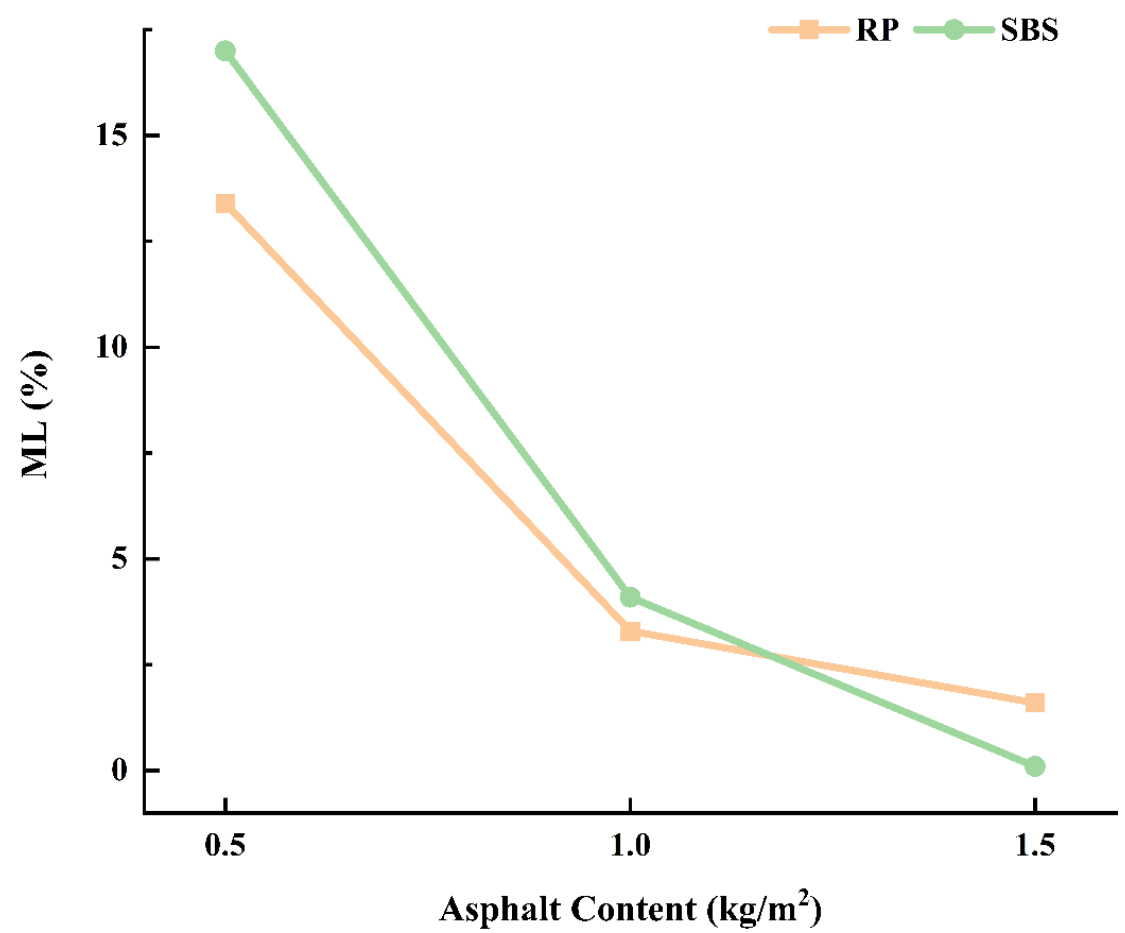

Figure 5. Brush damage test results under different asphalt content.

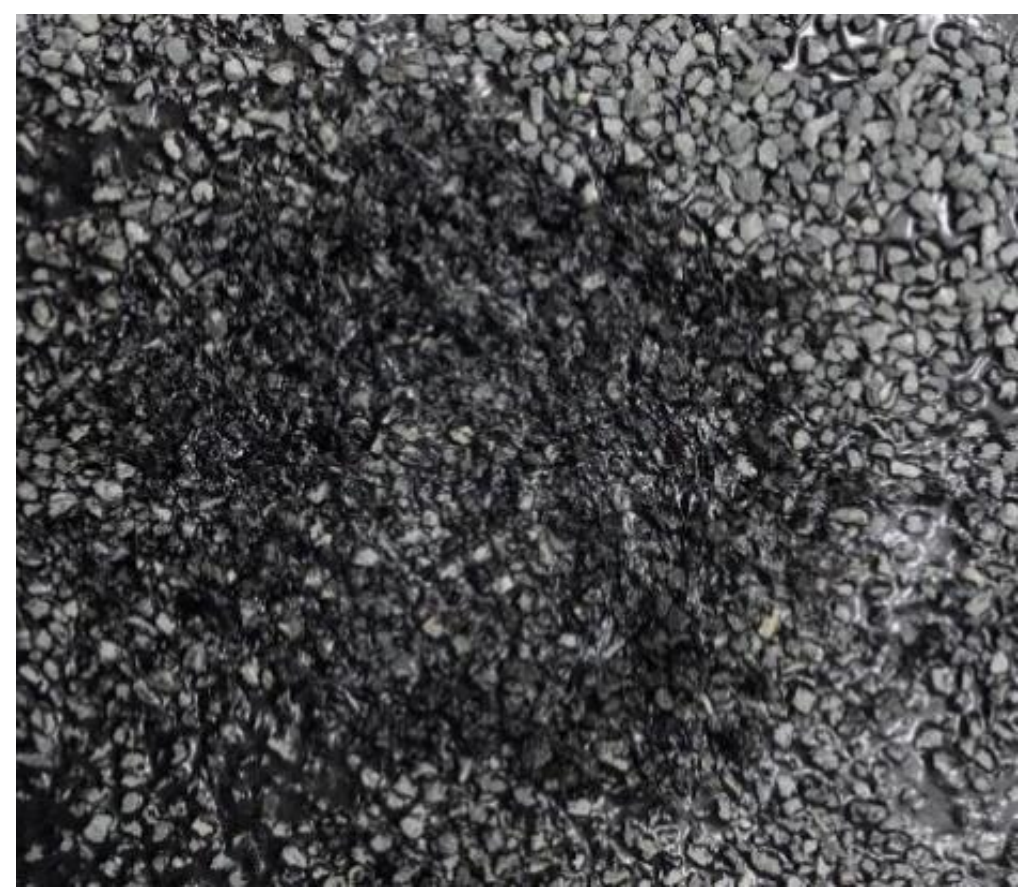

Figure 6. The surface condition of the sample after brushing under SBS asphalt content of $1.5 \mathrm{~kg} / \mathrm{m}^{2}$.

When the asphalt content was $1.0 \mathrm{~kg} / \mathrm{m}^{2}$, certain areas of the specimens using SBS had the same issues as when the asphalt content was $1.5 \mathrm{~kg} / \mathrm{m}^{2}$, and the experimental results of the two were not distinguishable. When the asphalt content was $0.5 \mathrm{~kg} / \mathrm{m}^{2}$, the thickness of the asphalt film was approximately $0.4 \mathrm{~mm}$. The asphalt was mainly bonded to the lower surface of the aggregate, and the primary damage that occurred during brushing was the 
adhesion failure between the asphalt and the aggregate, which corresponded to the actual outcome; the test results using different asphalt binders were significantly distinguishable. Hence, $0.5 \mathrm{~kg} / \mathrm{m}^{2}$ was recommended as the asphalt content for the brush damage test.

\subsubsection{Maintenance Temperature}

The maintenance temperature is the same as the test temperature. Four levels, $60{ }^{\circ} \mathrm{C}$, $65{ }^{\circ} \mathrm{C}, 70^{\circ} \mathrm{C}$ and $75^{\circ} \mathrm{C}$, were selected and compared, and four sets of specimens were formed using SBS and RP with 2.36-4.75 mm basalt aggregate. The other experimental conditions included a steel-wire brush, an asphalt content of $0.5 \mathrm{~kg} / \mathrm{m}^{2}$, and a maintenance time under wet conditions of $4 \mathrm{~h}$. The brush damage test results under different maintenance temperatures are shown in Figure 7.

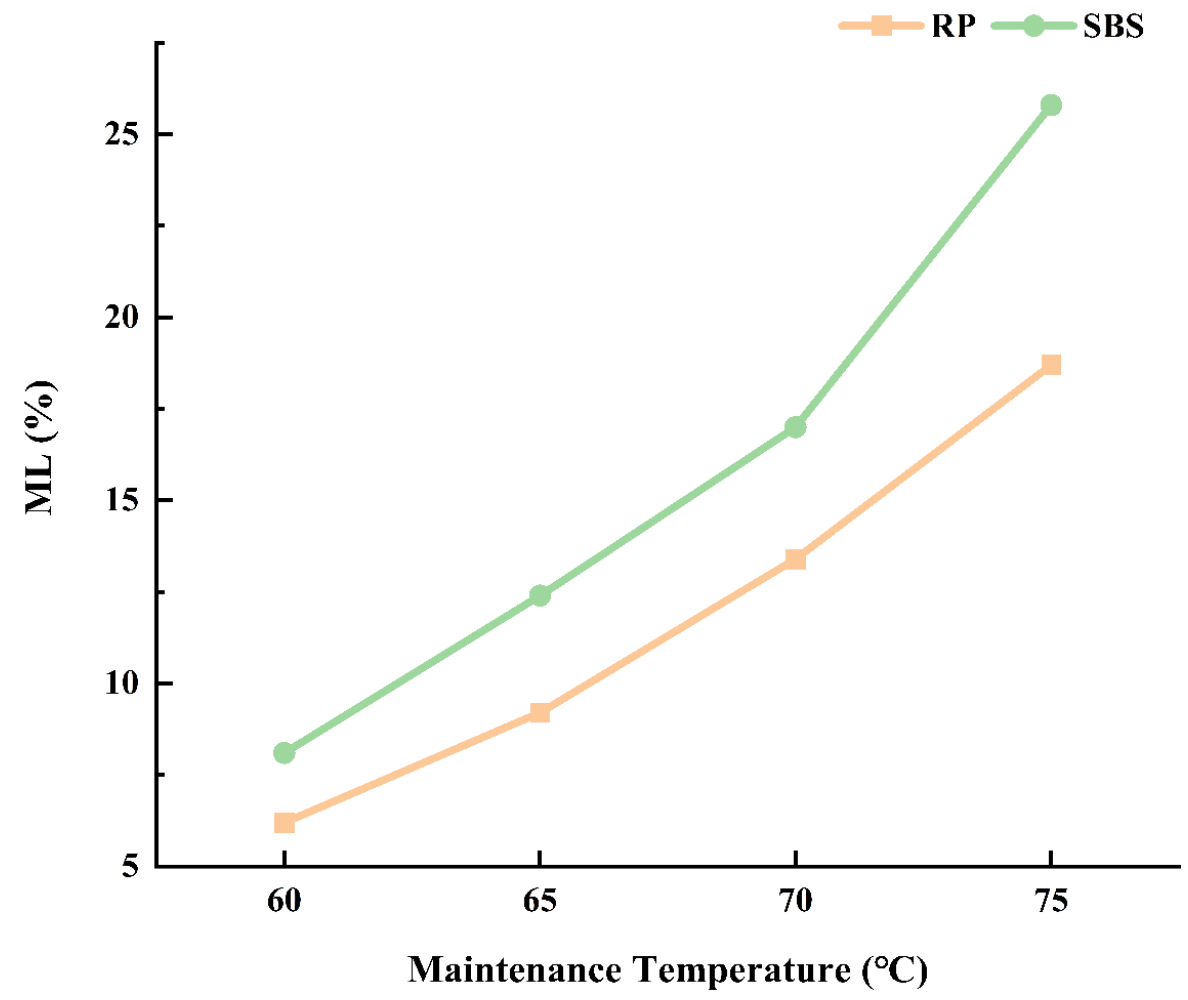

Figure 7. Brush damage test results under different maintenance temperatures.

As shown in Figure 7, the ML values were positively correlated with the maintenance temperatures, and as the temperature increased, the difference between ML values of specimens using the two asphalt binders increased as well. It was indicated that with the increase in maintenance temperature, the adhesion properties between asphalt and aggregate gradually deteriorated, and the adhesion property between SBS and aggregate deteriorated even more than that of RP.

According to theoretical predictions and statistical analysis, the highest surface temperature of asphalt pavement in southern China during the summer is between $60-70{ }^{\circ} \mathrm{C}[32,33]$. Based on consideration of the actual working conditions and adverse conditions, $70{ }^{\circ} \mathrm{C}$ was recommended as the maintenance temperature for the brush damage test.

\subsubsection{Maintenance Time}

Time periods of $2 \mathrm{~h}, 4 \mathrm{~h}$, and $8 \mathrm{~h}$ were selected and compared, and three sets of specimens were formed using SBS and RP with $2.36-4.75 \mathrm{~mm}$ basalt aggregate. The other experimental conditions included a steel-wire brush, an asphalt content of $0.5 \mathrm{~kg} / \mathrm{m}^{2}$, a maintenance condition of wet conditions, and a maintenance temperature of $70{ }^{\circ} \mathrm{C}$. The brush damage test results under different maintenance times are shown in Figure 8. 


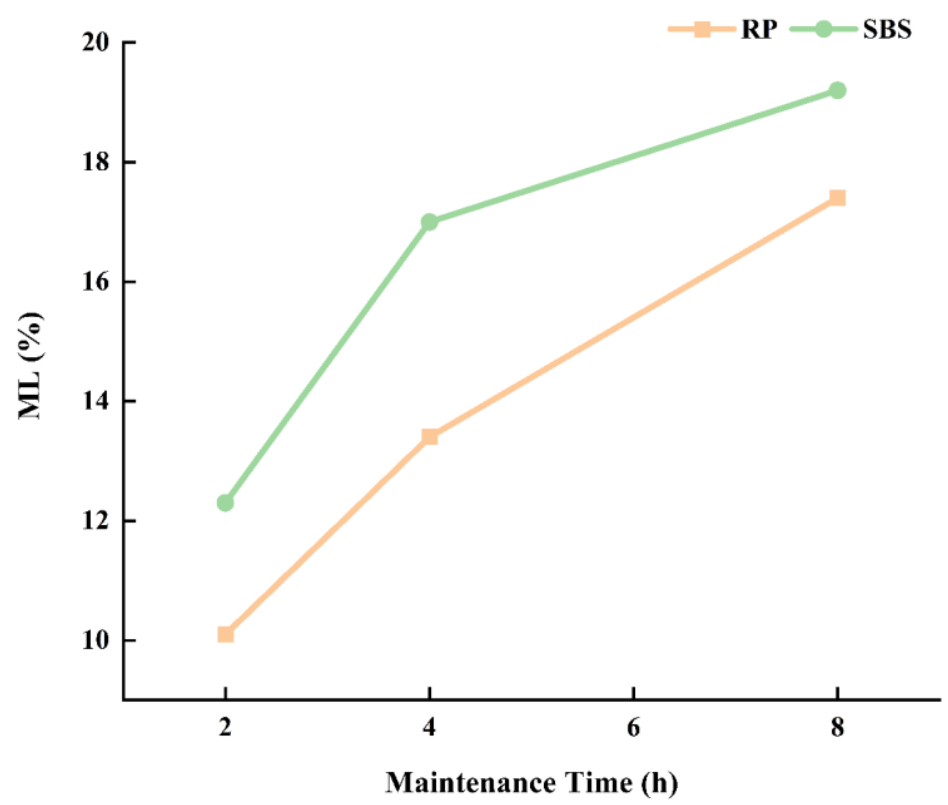

Figure 8. Brush damage test results under different maintenance times.

As shown in Figure 8, as the maintenance time increased, ML values gradually increased. Considering the full use of moisture in the wet condition to peel off the asphaltaggregate interface and shorten the test time, $4 \mathrm{~h}$ was recommended as the maintenance time for the brush damage test.

In summary, we found that the brush damage test proposed by this study would require a steel-wire brush, an asphalt content of $0.5 \mathrm{~kg} / \mathrm{m}^{2}$, a maintenance temperature of $70^{\circ} \mathrm{C}$, and a maintenance time of $4 \mathrm{~h}$.

\subsection{Analysis of the Brush Damage Test Results}

Ten sets of specimens were formed using 70\#, LDPE, SBS, CR, and RP with $2.36-4.75 \mathrm{~mm}$ basalt aggregate and limestone aggregate. The experimental conditions were a steelwire brush, an asphalt content of $0.5 \mathrm{~kg} / \mathrm{m}^{2}$, a maintenance temperature of $70{ }^{\circ} \mathrm{C}$, and a maintenance time under wet conditions of $4 \mathrm{~h}$. The brush damage test results are shown in Figure 9.

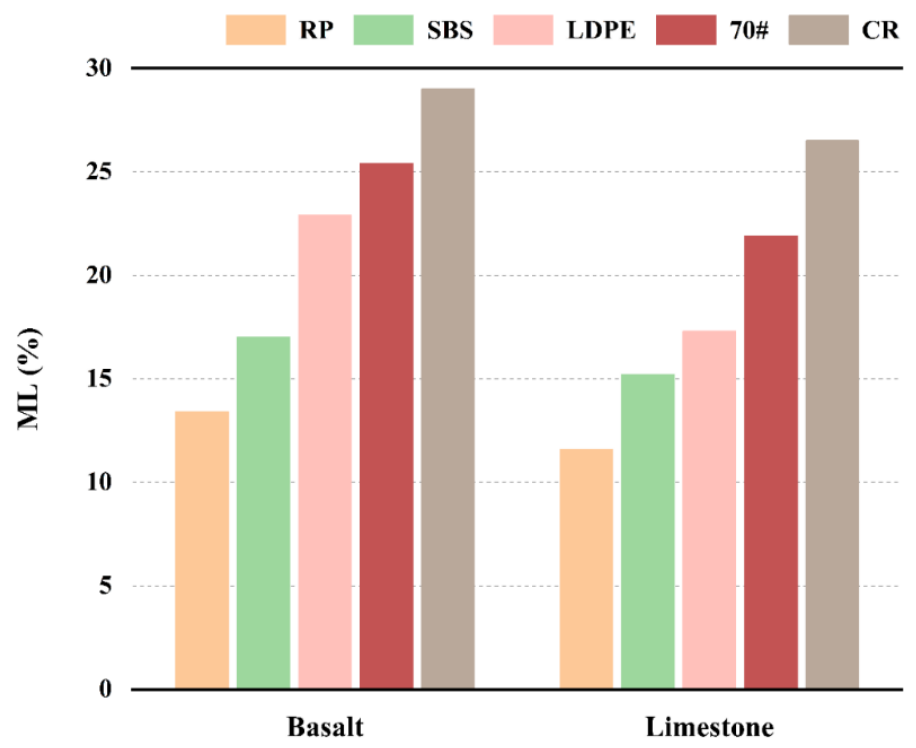

Figure 9. Brush damage test results of different asphalt binders. 
As shown in Figure 9, taking the mass loss rate (ML) of specimens as the evaluation index, the adhesion properties between asphalt and aggregate were ranked as follows: RP, SBS, LDPE, 70\#, and CR. Among these, CR had the largest ML value. Because the rubber existed in the asphalt in the form of crumbs, the asphalt film had an obvious graininess when preparing the specimen, which then had a negative impact on the adhesion property between the CR and the aggregate.

Bitumen is considered to be acidic. Under the same conditions, the adhesion property between asphalt and alkaline stones is better than that found with acid stones. As the surface-active sites of alkaline stones will chemically react with the acidic substances in the asphalt to form stable chemical bonds, this improves adhesion strength. Among the two aggregates used in this study the main component of limestone was calcium carbonate, which is a typical alkaline rock, and the silica content of basalt was generally $45-52 \%$, which is closer to neutral rock among alkaline rocks. As shown in Figure 9, the ML values of the specimens formed by the same asphalt binders and limestone aggregates were smaller than those of basalt aggregates, which meant that the adhesion properties of the five asphalt binders and limestone aggregates used in this test were better than those of basalt aggregates, which is consistent with scientific principles.

The test results indicated that the use of the brush damage test to evaluate the adhesion properties provided distinguishable results for different asphalt binders and different aggregates and had the advantages of high credibility and good discrimination.

\subsection{Comparison between Brush Damage Test and BBS Test}

The BBS test was performed with the PosiTest AT-A apparatus (Figure 10a) as recommended by ASTM D4541 [23]. In this study, basalt was selected as the stone substrate due to its wide usage in practice, the size of which was $100 \mathrm{~mm} \times 100 \mathrm{~mm} \times 10 \mathrm{~mm}$. The pull-out stubs were selected with an inner diameter of $18 \mathrm{~mm}$, an outer diameter of $20 \mathrm{~mm}$, and a groove depth of $0.2 \mathrm{~mm}$. The silicone molds were selected with an inner diameter of $21 \mathrm{~mm}$ in order to provide side limits. The preparation of the specimens and the BBS test were conducted according to the relevant study [34] and AASHTO TP-91 [24].

(1) Prepared three parallel specimens for each group.

(2) Cleaned the stone substrate and the pull-out stubs and preheated them with the base asphalt binders in an oven set to $160^{\circ} \mathrm{C}\left(180^{\circ} \mathrm{C}\right.$ for modified asphalt binders $)$ for $1 \mathrm{~h}$.

(3) Poured the liquid asphalt into the center of the silicone molds placed onto the stone substrate (Figure 10b), then placed the pull-out stubs on the asphalt (Figure 10c) and placed the same stone substrate on pull-out stubs to provide pressure (Figure 10d).

(4) Removed the upper stone substrate and silicone molds after maintaining at $25{ }^{\circ} \mathrm{C}$ for $1 \mathrm{~h}$.

(5) Under wet conditions, submerged the specimens in a water bath at $40{ }^{\circ} \mathrm{C}$ for $48 \mathrm{~h}$ and then maintained them at $25^{\circ} \mathrm{C}$ for $1 \mathrm{~h}$. Under dry conditions, hold the specimens at $25^{\circ} \mathrm{C}$ for $49 \mathrm{~h}$.

(6) Measured the pull-off tensile strength (POTS) at the loading rate of $0.7 \mathrm{Mpa} / \mathrm{s}$.

For the five types of asphalt binders used in this study, two groups, one wet and one dry, were prepared for the BBS test. The test results are shown in Figure 11. 


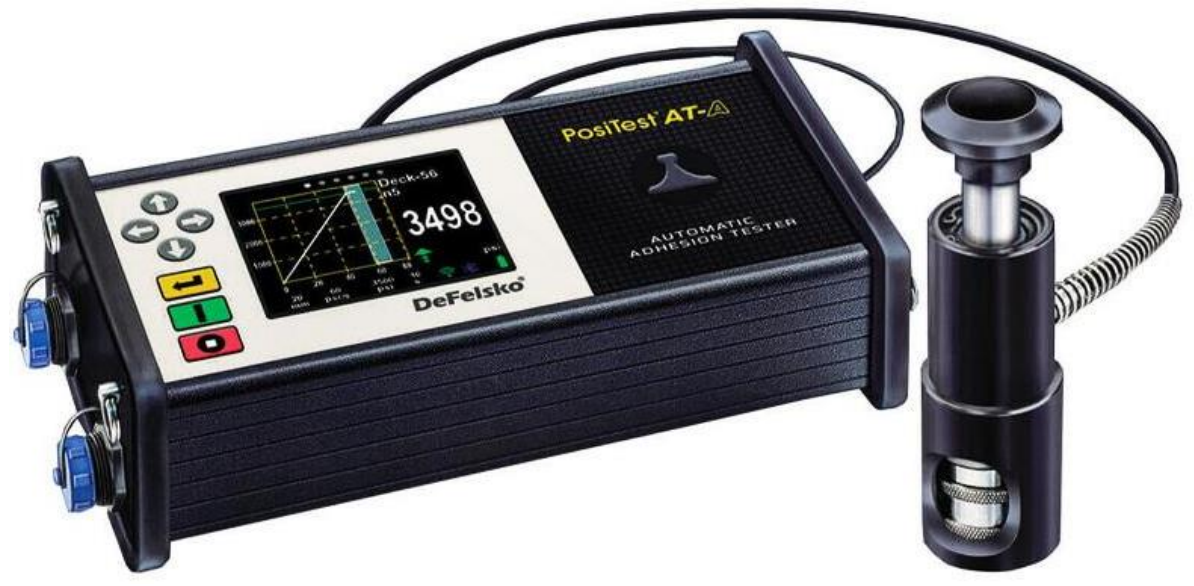

(a)

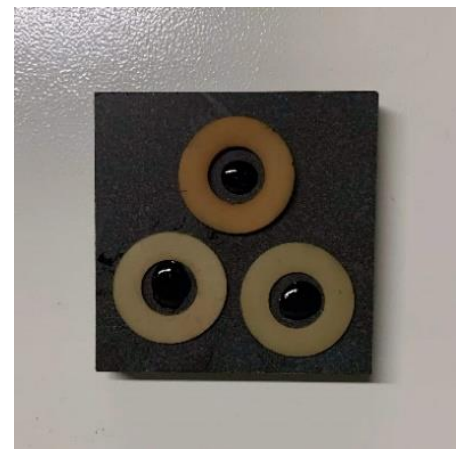

(b)

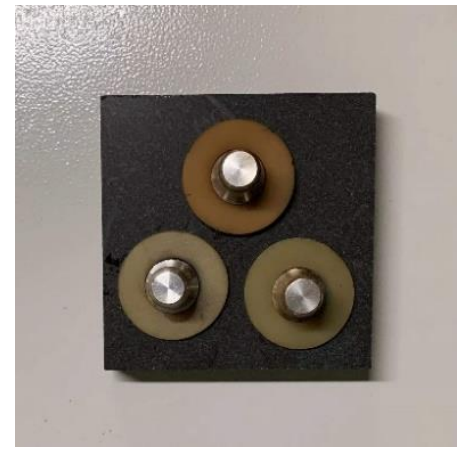

(c)

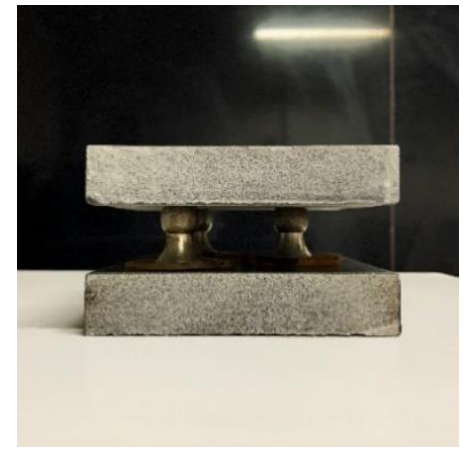

(d)

Figure 10. BBS test: (a) PosiTest AT-A; (b-d) preparation of sample.

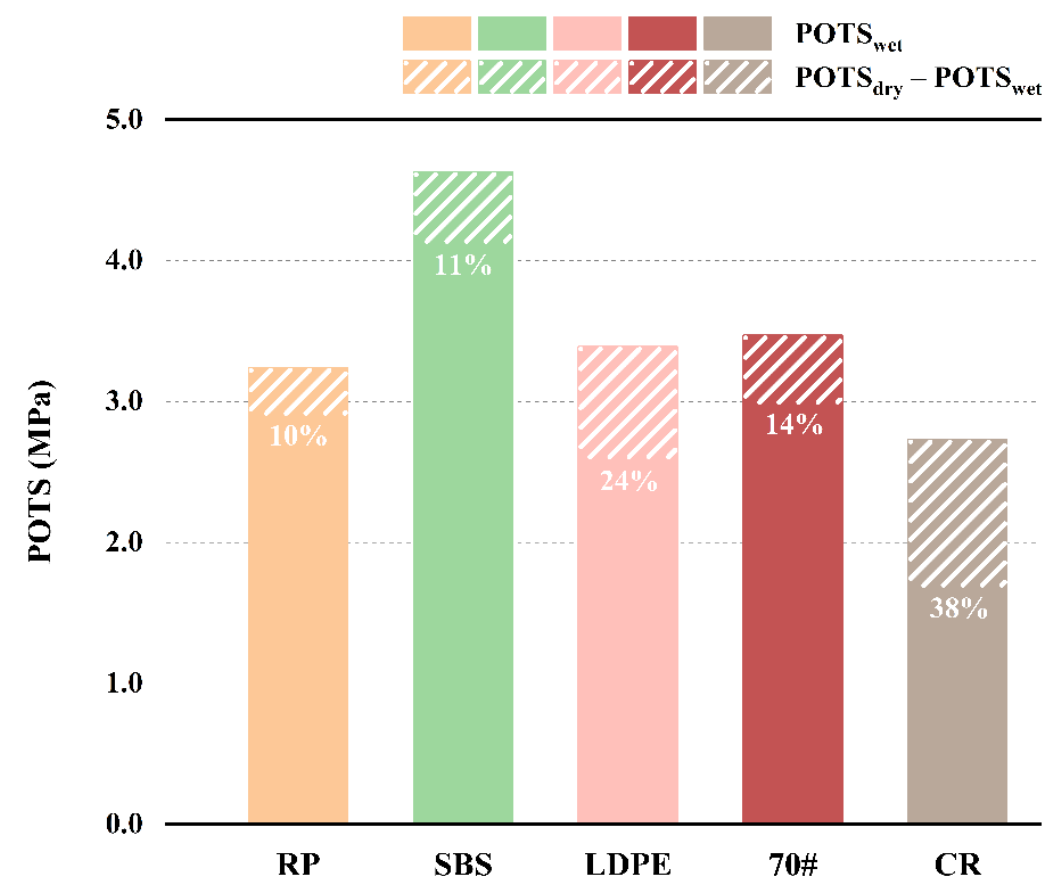

Figure 11. BBS test results of different asphalt binders.

POTS $_{\text {wet }}$ was the POTS value for the trial group with moisture damage (MPa). POTS was the POTS value for the control group without moisture damage (MPa). $\triangle \mathrm{POTS}$ was the 
POTS loss due to moisture damage (\%), calculated according to Equation (3) and marked as percentages in Figure 11.

$$
\Delta \mathrm{POTS}=\left(1-\frac{\text { POTS }_{\mathrm{wet}}}{\text { POTS }_{\mathrm{dry}}}\right) \times 100 \%,
$$

As shown in Figure 11, taking POTS $_{\text {wet }}$ as the evaluation index, the adhesion properties between asphalt and aggregate were ranked as follows: SBS, 70\#, RP, LDPE, and CR. Taking POTS $_{\text {dry }}$ as the evaluation index, the adhesion properties between asphalt and aggregate were ranked as follows: SBS, 70\#, LDPE, RP, and CR. Taking $\triangle P O T S$ as the evaluation index, the adhesion properties between asphalt and aggregate were ranked as follows: RP, SBS, 70\#, LDPE, and CR. We concluded that under different evaluation indexes, the ranking of the adhesion properties between asphalt and aggregate were not unified.

The results of CR were always the worst. This may be due to the thickness of the asphalt film being controlled at $0.2 \mathrm{~mm}$ and the crumbs of rubber being too large, which could affect the adhesion between the asphalt binders and the stone substrates.

The three indexes POTS $_{\mathrm{dry}}$, POTS wet $_{\text {P }}$ aPOTS) obtained from the BBS test and the index (ML) obtained from the brush damage test were subjected to linear fitting and Pearson's correlation analysis; the results are shown in Figure 12.

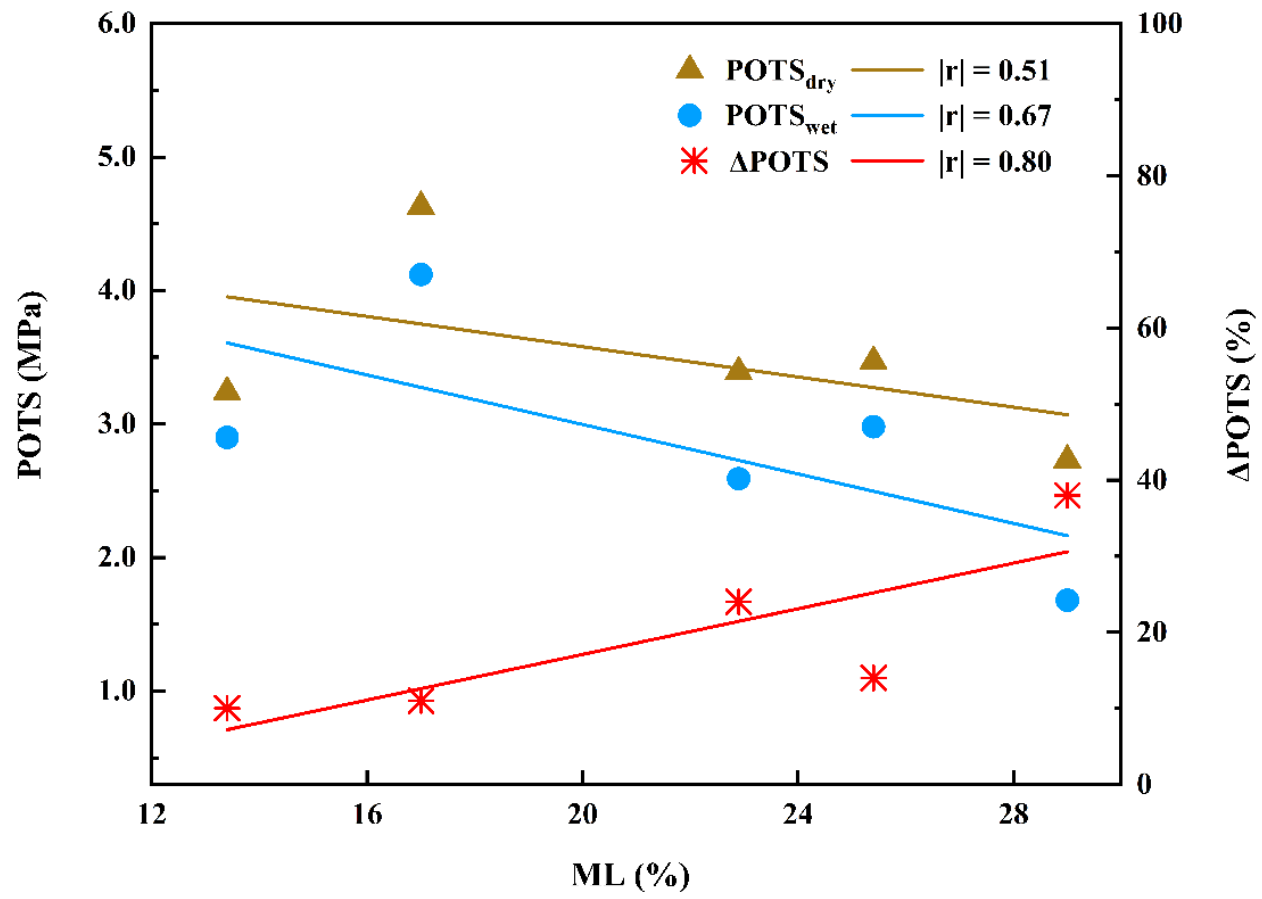

Figure 12. Correlation analysis of brush damage test results and BBS test results.

As indicated in Figure 12, the correlation coefficient $r$ between POTS dry $_{\text {and ML was }}$ only -0.51 , indicating that the pull-off tensile strength under dry conditions had a low correlation with the mass loss rate of brushing and could not be used as an index to evaluate the adhesion property of asphalt.

POTS $_{\text {wet }}$ was the most widely used evaluation index in the BBS test, as it reflected the bond strength between asphalt binders and stone substrates under water immersion condition and matched the disease generation mechanism of asphalt pavement being damaged by moisture. However, from the perspective of the correlation between POTS and ML based on actual working conditions, the smooth surface and single texture of the stone substrates selected in the BBS test did not reflect the true adhesion properties between asphalt and aggregate. The values of POTS $_{\text {wet }}$ were not reliable for evaluating adhesion properties. 
$\triangle$ POTS reflected the ability of asphalt to resist the loss of adhesion strength caused by moisture erosion. The smaller the value, the stronger the ability to resist moisture erosion and the better the adhesion property. As compared to POTS dry $_{\text {and }}$ POTS wet $_{\text {, which }}$ use absolute values to evaluate the adhesion strength, $\triangle$ POTS was a relative value, which weakened the influence of the contact surface properties in the adhesion behavior of asphalt and aggregate to a certain extent. Therefore, the correlation coefficient $r$ between $\triangle$ POTS and ML reached 0.80 , indicating the two had a strong correlation and could be used to evaluate the adhesion properties between asphalt and aggregate.

\section{Conclusions}

Based on the tests results of this study, the following conclusions were drawn:

(1) A method for evaluating the adhesion properties between asphalt and aggregate, the brush damage test, was proposed, and the mass loss rate (ML) of specimens through brushing was used as the evaluation index. In this study, the test equipment was independently developed. To simulate the actual working conditions with adhesion failures between asphalt and aggregate, the actual asphalt binders and aggregates used in the construction of asphalt pavement were selected, and the dry and wet conditions were set.

(2) For experimental conditions, the type of brush, the asphalt content, the maintenance temperature, and the maintenance time were determined. A steel-wire brush was recommended based on its stable shape and significant test results. As the asphalt content increased, the thickness of the asphalt film increased, and the test results were unable to reflect the actual moisture damage. Therefore, a total of $0.5 \mathrm{~kg} / \mathrm{m}^{2}$ of asphalt content was recommended. As the maintenance temperature and the maintenance time increased, the ML values increased. Considering the actual surface temperatures of asphalt pavements, sufficient bonding between asphalt and aggregate, and reducing the test time, $70^{\circ} \mathrm{C}$ and $4 \mathrm{~h}$ of maintenance temperature and time, respectively, were recommended.

(3) The brush damage test was performed on one base asphalt binder and four modified asphalt binders. Taking the mass loss rate (ML) of specimens as the evaluation index, the adhesion properties between asphalt and aggregate were ranked as follows: RP, SBS, LDPE, 70\#, and CR.

(4) The BBS test was conducted on the same five asphalt binders, and it was found that the evaluation results of adhesion properties between asphalt and aggregate were not consistent with the brush damage test. The pull-off tensile strength under dry conditions $\left(\right.$ POTS $_{\mathrm{dry}}$ ) had a poor correlation with ML. Although the pull-off tensile strength under wet conditions $\left(\right.$ POTS $_{\text {wet }}$ ) has been a popular index to evaluate adhesion properties, it ignores the influence of the actual texture of the aggregate. The credibility of the above two indexes to evaluate the adhesion properties between asphalt and aggregate was doubtful. $\triangle$ POTS represented the ability of asphalt to resist the loss of adhesion strength caused by moisture damage, which had a strong correlation with ML based on simulated actual working conditions and could be used as an evaluation index to evaluate the adhesion properties between asphalt and aggregate.

(5) On the basis of simulating actual working conditions, the brush damage test for evaluating the adhesion properties between asphalt and aggregate had the advantages of simple operation, high credibility, and good discrimination

Author Contributions: Conceptualization, X.D.; Data curation, J.L., M.S., S.W. and Z.F.; Formal analysis, J.L.; Investigation, J.L., M.S., S.W. and Z.F.; Methodology, M.S. and W.H.; Validation, J.L.; Writing—original draft, S.W. and Z.F.; Writing—review \& editing, J.L. and M.S. All authors have read and agreed to the published version of the manuscript.

Funding: This research received no external funding. 
Institutional Review Board Statement: Not applicable.

Informed Consent Statement: Not applicable.

Data Availability Statement: Not applicable.

Conflicts of Interest: The authors declare no conflict of interest.

\title{
Abbreviations
}

Abbreviation or Acronym
ML
BBS
POTS $_{\text {dry }}$
POTS $_{\text {wet }}$
POTS
LDPE
SBS
CR
RP

\author{
Full Name \\ Mass loss rate \\ Binder bond strength \\ Pull-off tensile strength under dry conditions \\ Pull-off tensile strength under wet conditions \\ Pull-off tensile strength \\ Low density polyethylene \\ Styrene-butadiene-styrene block copolymer \\ Crumb rubber \\ Rubber plastic powder
}

\section{References}

1. Haider, S.; Hafeez, L.; Jamal; Ullah, R. Sustainable use of waste plastic modifiers to strengthen the adhesion properties of asphalt mixtures. Constr. Build. Mater. 2020, 235, 117496. [CrossRef]

2. Ameri, M.; Ziari, H.; Yousefi, A.; Behnood, A. Moisture susceptibility of asphalt mixtures: Thermodynamic evaluation of the effects of antistripping additives. J. Mater. Civ. Eng. 2021, 33, 4020457. [CrossRef]

3. Ghabchi, R.; Singh, D.; Zaman, M. Laboratory evaluation of stiffness, low-temperature cracking, rutting, moisture damage, and fatigue performance of WMA mixes. Road Mater. Pavement Des. 2015, 16, 334-357. [CrossRef]

4. Chu, L.; Luo, L.; Fwa, T.F. Effects of aggregate mineral surface anisotropy on asphalt-aggregate interfacial bonding using molecular dynamics (MD) simulation. Constr. Build. Mater. 2019, 225, 1-12. [CrossRef]

5. Junior, J.; Babadopulos, L.; Soares, J.B. Influence of aggregate-binder adhesion on fatigue life of asphalt mixtures. J. Test. Eval. 2020, 48, 150-160.

6. Research Institute of Highway Ministry of Transport. Standard Test Methods of Bitumen and Bituminous Mixtures for Highway Engineering (JTG E20-2011); China Communications Press: Beijing, China, 2011.

7. Valentin, J.; Trejbal, J.; Nezerka, V.; Valentova, T.; Vackova, P.; Ticha, P. A comprehensive study on adhesion between modified bituminous binders and mineral aggregates. Constr. Build. Mater. 2021, 305, 124686. [CrossRef]

8. Mccann, M.; Sebaaly, P. Quantitative evaluation of stripping potential in hot-mix asphalt, using ultrasonic energy for moistureaccelerated conditioning. Transp. Res. Rec. J. Transp. Res. Board 2001, 1767, 48-49. [CrossRef]

9. Vuorinen, M.; Hartikainen, O. A new ultrasonic method for measuring stripping resistance of bitumen on aggregate. Road Mater. Pavement Des. 2011, 2, 297-309. [CrossRef]

10. Curtis, C.W.; Ensley, K.; Epps, J. Fundamental Properties of Asphalt-Aggregate Interactions including Adhesion and Absorption (SHRP-A341); National Research Council: Washington, DC, USA, 1993.

11. Kavussi, A.; Naderi, B. Application of SCB Test and Surface Free Energy Method in Evaluating Crack Resistance of SBS Modified Asphalt Mixes. Civ. Eng. Infrastruct. J. 2020, 53, 103-114.

12. Tanzadeh, R.; Shafabakhsh, G. Surface free energy and adhesion energy evaluation of modified bitumen with recycled carbon black (micro-nano) from gases and petrochemical waste. Constr. Build. Mater. 2020, 245, 118361. [CrossRef]

13. Al-Saffar, Z.H.; Yaacob, H.; Satar, M.K.I.M.; Jaya, R.P. Impacts of maltene on the wettability and adhesion properties of rejuvenated asphalt binder. Arab. J. Sci. Eng. 2021, 46, 1-12. [CrossRef]

14. Wei, J.; Zhang, Y. Application of sessile drop method to determine surface free energy of asphalt and aggregate. J. Test. Eval. 2012, 40, 807-813. [CrossRef]

15. Soenen, H.; Vansteenkiste, S.; Kara De Maeijer, P. Fundamental Approaches to Predict Moisture Damage in Asphalt Mixtures: State-of-the-Art Review. Infrastructures 2020, 5, 20. [CrossRef]

16. Allen, R.G.; Little, D.N.; Bhasin, A. Structural characterization of micromechanical properties in asphalt using atomic force microscopy. J. Mater. Civ. Eng. 2012, 24, 1317-1327. [CrossRef]

17. Ji, X.P.; Li, J.; Zhai, X.G.; Zou, H.W.; Chen, B. Application of atomic force microscope to investigate the surface micro-adhesion properties of asphalt. Materials 2020, 13, 1736. [CrossRef]

18. Nazzal, M.D.; Abu Qtaish, L.; Al-Hosainat, A.; Abu Talha, S.; Abbas, A. Evaluation of moisture damage in asphalt mixtures at macro- and nanoscales. J. Mater. Civ. Eng. 2021, 33, 04021369. [CrossRef]

19. Wang, Y. Study on Adhesion between Asphalt and Aggregate Using Surface Energy Theory. Master's Thesis, Hunan University, Hunan, China, 2010. 
20. Wang, W.N.; Xu, Q.J.; Zhou, S.X.; Qin, Y.; Yan, Q. A review on evaluation methods of asphalt-aggregate adhesion. Mater. Rev. 2019, 33, 2197-2205.

21. Lacombe, R. Adhesion Measurement Methods: Theory and Practice; CRC Press Taylor \& Francis Group: Boca Raton, FL, USA, 2006.

22. Wang, Y. The Bonding Characteristic Research of Aggregate-Asphalt Mortar Interface. Master's Thesis, Harbin Institute of Technology, Harbin, China, 2015.

23. American Society of Testing Materials ASTM D4541, Standard Test Method for Pull-Off Adhesion Strength of Coatings on Concrete Using Portable Pull-Off Adhesion Testers; American Society of Testing Materials: West Conshohocken, PA, USA, 2009.

24. AASHTO TP-91, Standard Method of Test for Determining Asphalt Binder Bond Strength by Means of the Binder Bond Strength (BBS) Test; American Association of State Highway and Transportation Officials: Washington, DC, USA, 2011.

25. Lv, Q.; Huang, W.D.; Sun, L.J.; Zhou, L.; Liu, L.Y. Evaluation and mechanism analysis of adhesive self-healing property of asphalt. J. Harbin Inst. Technol. 2021, 53, 33-41.

26. Guo, M.; Tan, Y.Q.; Zhou, S.W. Multiscale test research on interfacial adhesion property of cold mix asphalt. Constr. Build. Mater. 2014, 68, 769-776. [CrossRef]

27. Khasawneh, M.A.; Al-Oqaily, D.M.; Abu Alia, A.H.; Al-Omari, A.A. Evaluation of aggregate-binder bond strength using the bbs device for different road materials and conditions. Int. J. Pavement Eng. 2021, 107, 2411-2502. [CrossRef]

28. Chaturabong, P.; Bahia, H.U. Effect of moisture on the cohesion of asphalt mastics and bonding with surface of aggregates. Road Mater. Pavement Des. 2018, 19, 741-753. [CrossRef]

29. Mogawer, W.S.; Austerman, A.J.; Bahia, H.U. Evaluating the effect of warm-mix asphalt technologies on moisture characteristics of asphalt binders and mixtures. Transp. Res. Rec. J. Transp. Res. Board 2011, 2209, 52-60. [CrossRef]

30. Aguiar-Moya, J.P.; Loria-Salazar, L.; Salazar, J.; Corrales-Azofeifa, J.; Villegas, E.; Corrales-Azofeifa, J.P.; Hajj, E.Y. Evaluation of Adhesion Properties of Costa Rican Asphalt Mixtures Using the Bitumen Bond Strength (BBS) and Contact Angle Measurement Tests. Presented at the 92nd Annual Meeting of the Transportation Research Board, Washington, DC, USA, 13-17 January 2013.

31. Mishra, V.; Singh, D. Evaluating factors affecting aggregate-bitumen interfacial strength using binder bond-strength test. J. Mater. Civ. Eng. 2021, 33, 04021089. [CrossRef]

32. Li, Z.; Zhang, Y.; Fa, C.; Zou, X.; He, R. Investigation on the temperature distribution of asphalt overlay on the existing cement concrete pavement in hot-humid climate in southern China. Adv. Civ. Eng. 2021, 2021, 1-12. [CrossRef]

33. Fu, J.; Liu, Z.H.; Zuo, X.N.; Lai, Z.H.; Wang, X.Z.; Ding, Q.J. Influence of regional climate change on summer temperature effect of asphalt pavement. J. Chongqing Univ. (Nat. Sci.) 2020, 39, 87-94.

34. Huang, W.D.; Zhou, L. Evaluation of adhesion properties of modified asphalt binders with use of binder bond strength test. Transp. Res. Rec. J. Transp. Res. Board 2017, 2632, 88-98. [CrossRef] 